\title{
Model of Knowledge Management via Social Media to Enhance Graduated Student's Self-Directed Learning Skill
}

\author{
Nattaphon Rampai
}

\begin{abstract}
This research aims to develop the model of knowledge management and social media technology that appropriate with teaching and learning for graduated student, in particular to enhance graduated student's self-directed learning skill and practices that including knowledge management process: creating, analyzing, nurturing, disseminating, and optimizing as part of the teaching and learning activity. In this process which driven by social media tools: Facebook, twitter, YouTube, Wikis, and blogs it's has a necessary role to drive and integrate knowledge and learning activities within the knowledge management process, and the self-directed learning skill steps included planning, strategy, motivation, monitoring, evaluating, and summary. In this respect, this research explored the appropriate model of knowledge management via social media that enhance the graduate student's self-directed learning skill.
\end{abstract}

Index Terms-Knowledge management via social media, self-directed learning skill, graduated student.

\section{INTRODUCTION}

Graduate student quality is the top contributing factor to student achievement. Quality ongoing professional development contributes to student growth and success. The needs for professional development that can meet today's educators' demanding schedules, that uses quality content and resources that are available to teachers from any place and any time, and that can deliver relevant, accessible, and ongoing support has stimulated the development of online teacher professional development programs. Online teacher professional development programs make it possible for educators to communicate, share knowledge and resources, and reflect via asynchronous interactions. Moreover, [1] suggest that the many current ICT-supported reform efforts demand teachers to assume the role of epistemic facilitator of knowledge construction supported by technology. In addition, [2] explored the characteristics of such technology training programs were discussed to help students learn how to use technologies as instructional tools to enhance their teaching and students' learning. The condition of education in Thailand today still has several problems. Especially, the quality of learners seems shortages [3]. Along with the lack of pedagogy skills that is not match in the actual practical needs for higher education. Particularly, the lack of the self-directed learning skill of graduate students to use that knowledge management let the opportunity to exchange and

Manuscript received May 4, 2014; revised July 20, 2014.

N. Rampai is with the Department of Educational Technology, Kasetsart University, Bangkok, Thailand, 10900 (e-mail: fedunpra@ku.ac.th). share knowledge is decreased between them and focuses on the upstream of training from real situations process furthermore, [4] have suggests that the common difficulties and limitations regarding the implementation of knowledge management into classrooms cultures. In addition, [5] exhibited that students' collective inquiry relied on socially distributed cognitive resources that were generated by their social interactions in class and online using technology. The concept of social media that based on the appropriate tool and the medium to deliver knowledge, and helps learners can communicated with each other [6] especially in teaching and learning using the potential of internet network to access with various sources of learning [7]. The main purpose of this study is to research and develop activities to be appropriate with the learners that integrated with the concept of knowledge management and social media. The question then becomes, "How to develop the appropriate model of knowledge management via social media". The expected benefits are the appropriate model that is the systematic approach to enhance graduated student's self-directed learning skill. More over the results of quality assessment of model that is body of knowledge to develop the learning skill of graduated students. In addition the results can be the information to support the higher education systems policy maker.

\section{OBJECTIVES}

This research aims to

1) Study the model of knowledge management via social media to enhance graduated student's self-directed learning skill.

2) Develop knowledge management system via social media to enhance graduated student's self-directed learning skill

3) Evaluate the result of knowledge management via social media model to enhance graduated student's self-directed learning skill.

\section{Methodology}

The $1^{\text {st }}$ phase focus to study the model of knowledge management via social media to enhance graduate student's self-directed learning skill.

1) Analyzing the elements of knowledge management (KM) are included the knowledge management activities: Creating (Explore and Capture), Analyzing (Identify and Organize), Nurturing (Utilize and Demonstrate), Disseminating (Transfer and Diffuse), and Optimizing 
(Evaluate and Improve) and designed activity in to the Social media.

2) Analyzing the elements of social media are included the elements of Social media that designed to fit the model (Facebook, Tweeter, YouTube, Wikis, and Blogs).

3) Analyzing the elements of self-directed learning skill by the matrix analysis table and checked list high frequency items or elements in to the next step.

4) Integrating the elements of knowledge management, social media and self-directed learning skill by the matrix analysis technique.

5) Studying the appropriate quality of web site that based on the model of knowledge management via social media to enhance graduate student's self-directed learning skill by the 3 experts (Educational technology and Knowledge Management field).

The $2^{\text {nd }}$ phase go for develop the model of knowledge management via web-based learning to enhance graduate student's self-directed learning skill and assessment tools.

1) Developing the web site based on the model of knowledge management via social media and quality evaluated by the 3 experts (Educational technology and Knowledge Management field).

2) Developing the graduated student's ability on self-directed learning skill form, and the graduated student's self-directed learning skill form by the 42 graduate students who study in semester, 2012 for study the research tools quality (try-out methods).

3) Studying the efficiency of web site that based on the model of knowledge management via social media to enhance graduate student's self-directed learning skill.

4) Preparing the all of research tools which using in the next phase

Finally, the $3^{\text {rd }}$ phase is to evaluating the model of knowledge management via social media to enhance graduate student's self-directed learning skill.

1) Research design by following the Two-Group Posttest Only Design.

2) Population and samples:

a) Population is the graduate students (Master and degree) who study in semester, 2013 academic year at Faculty of Education, Kasetsart University, Thailand.

b) Samples are 30 graduate students that collected by random sampling technique and learn with the model of knowledge management via web-based learning to enhance graduate student's self-directed learning skill.

3) Research tools:

a) Web site that based on the model of knowledge management via social media.

b) The graduated student's ability on self-directed learning skill form.

c) The graduated student's self-directed learning skill form.

4) Data analysis:

a) Descriptive statistics were Arithmetic Mean $(\bar{X})$ and Standard Deviation (S.D.) are used to describe the basic features of the quantitative data.

b) Qualitative data were analyzed by category group and issuing data technique.

\section{RESULtS}

1) The model of knowledge management via social media to enhance graduate student's self-directed learning skill was appropriated with the criterion of quality, detail are as follow:

a) Knowledge management are include the KM activities of Creating (Explore and Capture), Analyzing (Identify and Organize), Nurturing (Utilize and Demonstrate), Disseminating (Transfer and Diffuse), and Optimizing (Evaluate and Improve).

b) Social media are driven the Knowledge management by the tools/ channel/ media which focus on Facebook, Tweeter, YouTube, Wikis, and Blogs.

c) Self-directed learning skill are including the components of Planning, Strategies, Resources, Motivation, Monitoring, Evaluating, and Summary (details see Fig. 1)

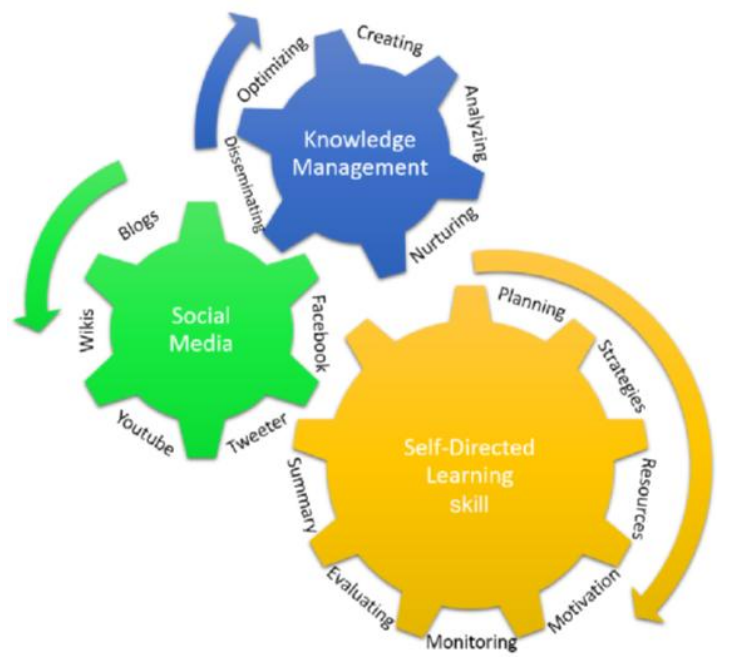

Fig. 1. The model of knowledge management via social media to enhance graduate student's self-directed learning skill.

2) The Quality of model of knowledge management via social media to enhance graduate student's self-directed learning skill by the 6 experts (Educational technology and Knowledge Management field) was appropriated with instructional media showed overall results quality at highest level (mean=4.51, S.D.=0.54), details are following: the highest level showed at process step (mean=4.61, S.D.=0.54), the overview of the basic elements of the model (mean=4.52, S.D.=0.59), the overall of productivity (output) step (mean=4.50, S.D.= 0.56 ), the overall of the input step (mean $=4.40$, S.D. $=0.58$ ) and totally, model that mean the model of knowledge management via social media can supports the student to learn and enhance their self-directed learning skill on the next steps.

3) The model of knowledge management via social media showed appropriate quality at highest level (mean $=4.55$, S.D.=0.56) and its was appropriated with the volunteer participants' self-directed learning skill that showed efficiency at 86.77/85.77 (details see on Table I) which based on the criteria of instructional system design which based on 85/ 85 Standard [8] and [9] that mean the model of knowledge management via social media can 
utilize for the graduate students on the next steps.

TABLE I: THE EFFICIENCY WHICH BASED ON THE CRITERIA

\begin{tabular}{|c|c|c|}
\hline Total of students & $\begin{array}{c}\text { Activity and practice } \\
\text { scores }\left(E_{\mathbf{1}}\right)\end{array}$ & $\begin{array}{c}\text { Posttest scores } \\
\left(E_{2}\right)\end{array}$ \\
\hline$(\Sigma \mathrm{X})$ & 781 & 772 \\
\hline$(\bar{X})$ & 26.03 & 25.73 \\
\hline$(n=30)$ & & \\
\hline
\end{tabular}

$$
\begin{aligned}
& E_{1}=\frac{\frac{\sum X}{n}}{A} \times 100=\frac{26.03}{30} \times 100=86.77 \\
& E_{2}=\frac{\frac{\sum X}{n}}{B} \times 100=\frac{25.73}{30} \times 100=85.77
\end{aligned}
$$

The efficiency which based on the criteria of instructional system design $\left(E_{1} / E_{2}\right)=86.77 / 85.77$

4) The student's self-directed learning on design and development ability skills who learn by the web site that based on model of knowledge management via social media showed at highest level $($ mean $=3.52 / 4.00)$, details are following: the ability to completely products indicators showed at highest level (mean $=3.62 / 4.00)$, the concentration to produce with continuing indicators showed at highest level (mean $=3.56 / 4.00)$, and the creativity to selected tools to produce with efficiency $($ mean $=3.38 / 4.00)($ details see on Table II $)$

TABLE II: THE RESULT OF STUDENT'S SELF-DIRECTED LEARNING ON DESIGN AND DEVELOPMENT ABILITY SKILL

\begin{tabular}{|c|c|c|c|c|c|}
\hline $\begin{array}{c}\text { Total of } \\
\text { students }\end{array}$ & $\begin{array}{c}\text { Sum of } \\
\text { skill \# } \mathbf{1}\end{array}$ & $\begin{array}{c}\text { Sum of } \\
\text { skill \# 2 }\end{array}$ & $\begin{array}{c}\text { Sum of } \\
\text { skill \# 3 }\end{array}$ & Total & Level \\
\hline 42 & 3.62 & 3.38 & 3.56 & 3.52 & Highest \\
\hline$(n=42)$ & & & & & \\
\hline
\end{tabular}

5) The student's self-directed learning skills who learn by the web site that based on model of knowledge management via social media as a result, most of students had increased the self-directed learning skills at high level $($ mean=4.31, S.D. $=0.11)$

\section{CONCLUSIONS}

Research results exhibited that the model of knowledge management via social media to enhance graduate student's self-directed learning skill was appropriated and fit to the quality of educational media. Online learning skills development is an emerging trend it is still a "new frontier" [10]. Educators around the world experience many demands on their knowledge, time, and professional development. Developing and sustaining an effective online learning community can be challenging even in the midst of an era of much technological advancement [11]. More over developing and sustaining an effective large-scale online community is even more challenging. In addition, professional development has mainly centered on learning processes that involve updating knowledge, yet it has made little headway as a construct that includes both the professional and personal characteristics and working conditions. It has also focused more on developing. Finally, [12] suggest the online learning technologies have the potential to transform the professional development of students; penetrate cultural, discipline, and other barriers; bring educators together to learn, share successes and challenges; and co-construct and transfer learning.

\section{RESEARCH CONTRIBUTION AND RECOMMENDATIONS}

1) Application forms for knowledge management through social media to enhance the learning skills of the students' self-directed learning and teaching for design and development using web-based instruction. For graduate students appropriately. Which guide the application of the next future to teaching in higher education institutions.

2) Website database through social media, knowledge management, learning skills that strengthen self. Knowledge and wisdom which is important and relevant information. Knowledge of Information and wisdom in different fields of teaching in postgraduate studies.

3) Best practice to develop a model of knowledge management through social media to enhance the learning skills of the students' self in other appropriately graduate courses.

4) Guidelines for the strengthening of social networking online cooperation agency enterprise to search knowledge and sharing among learners in the format as a learning center.

\section{ACKNOWLEDGEMENTS}

The authors wish to thanks the Department of Educational Technology for their supported. This research was funded and supported by Research \& Development Institute, Faculty of Education and Graduate School, Kasetsart University, Thailand.

\section{REFERENCES}

[1] N. Dabner, "Design to support distance teacher education communities: A case study of a student-student e-mentoring initiative," in Proc. Society for Information Technology and Teacher Education International Conference 2011, Nashville, 2011, TN: AACE 1-880094-84-3.

[2] N. E. Davis, N. Dabner, J. Mackey et al., "Converging offerings of teacher education in times of austerity: Transforming spaces, places and roles," in Proc. Society for Information Technology and Teacher Education International Conference 2011, Nashville, 2011, TN: AACE 1-880094-84-3.

[3] Secretariat of the Council of Education, "Report to the Thai Public Education Environment: Reform Knot," Bangkok: Primdee publications, 2010.

[4] C. L. Lee et al., "A process-based knowledge management system for schools: a case study in Taiwan," TOJET: The Turkish Online Journal of Educational Technology, vol. 9, iss. 4, October 2010.

[5] H. Erkunt, "Emergence of epistemic agency in college level educational technology course for pre-service teachers engaged," TOJET: The Turkish Online Journal of Educational Technology, vol. 9, iss. 3, July 2010.

[6] P. Catherall, Delivering E-learning for Information Services in Higher Education, Oxford: Chandos Publishing, 2008.

[7] V. S. Belleghem, "Social Media around the world 2011," The report by InSites Consulting, 2011.

[8] C. Brahmawong, Production of E-learning Courseware, Nontaburi: Sukhothai Thammathirat Open University Press, 2002. 
[9] K. Whattananarong, "The effects of internet-based teaching and learning systems on learners," The Journal of King Mongkut's Institute of Technology North Bangkok, vol. 14, no. 3, pp. 32-39, Jul.-Sept. 2004

[10] R. Keawdang, Revolutionize education Thailand, Bangkok: Matichon Publishing, 2009.

[11] C. S. Chai, "Teachers' epistemic beliefs and their pedagogical beliefs: A qualitative case study among singaporean teachers in the context of ICT-supported reforms," TOJET: The Turkish Online Journal of Educational Technology, vol. 9, iss. 4, October 2010.

[12] M. Koc and N. Bakir, "A needs assessment survey to investigate pre-service teachers' knowledge, experiences and perceptions about preparation to using educational technologies," TOJET: The Turkish Online Journal of Educational Technology, vol. 9, iss. 1, January 2010

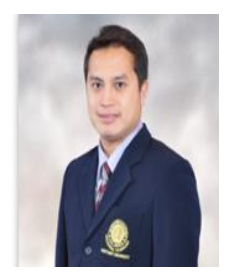

Nattaphon Rampai was born on March 2, 1980. He received his B.Sc.Ind.Ed. in industrial education, King Mongkut Thonburi University of Technology, Bangkok in 2003, and M.Ed. in educational technology, Kasetsart University , Bangkok in 2005 , and Ed.D. in educational technology, Kasetsart University, Bangkok in 2011. 